\title{
Rattlesnakes in Saskatchewan
}

By J. J. Deck, Mendham.

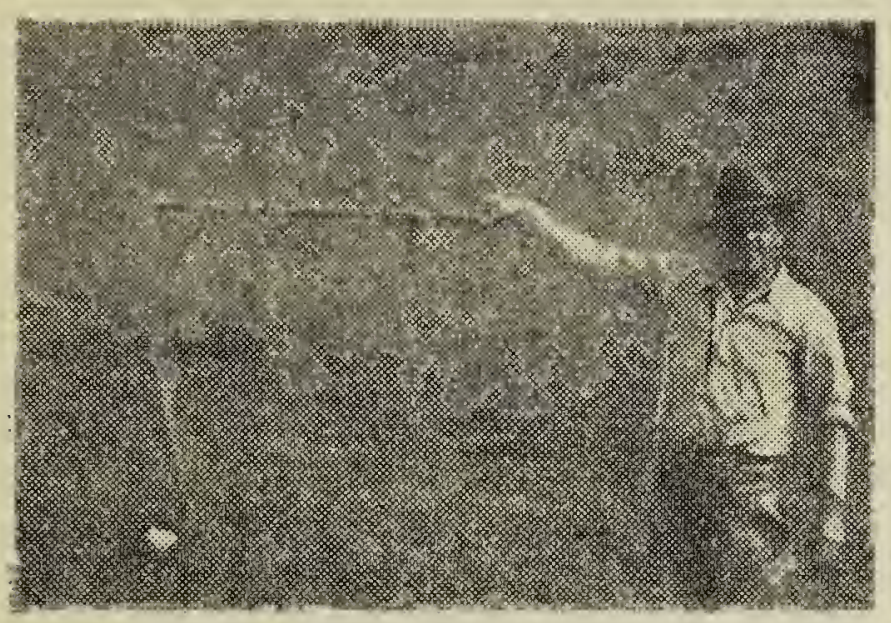

A four-footer held by the head with my catching stick.

A BOU'i ten miles west of this town, among the sand hills and nearer to the south branch of the Saskatchewan River, I have seen and caught many rattlesnakes. In all I have seen about three kinds of these snakes but no Black Diamonds are to be found in this district.

As the years pass the rattlesnakes are moving to areas further east and north, following in the general direction of the river. I have seen snakes swim across the river on three different occasions. Depending on the swiftness of the current, they will land some distance down stream on the other side.

In the fall of the year they move back from the sand hills, towards the river, to den in for the winter. The dens are difficult to find but at certain times in October, on fine days, ore can find nearly all the snakes one cares to see, close to the river. I engineered the killing of about fifty there in less than an hour.

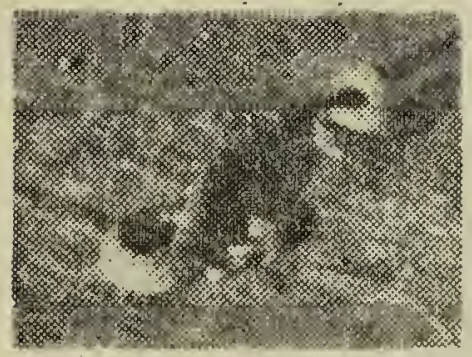

A rattlesnake usually gives one sufficient warning but on occasion I $\mathrm{h}$ a ve n e a r ly stepped on one before it sound ed the Ready to Strike alarm. To take a picture of one a person can get up very close if he is daring enough, because the snake has to curl up to strike. They can do this very fast- lightning fast-but they can only strike out about one-third of their length, and that they will do only when teased, otherwise they make short jabs.

Ranchers report that they have lost cattle from snake bite. These cases, however, appear to be very rare. Horses are also scared and will shy off fast when they discover that a snake is close. Pigs, however, will make short work of the snake and will eat them. Snake venom will not affect them.

There have been a few cases of persons being bitten but not many. I know of three cases in about eight years. Of these three, one was an adult and two were children. It seems that the adult got too daring and tried to catch a medium sized snake by the tail. It snapped back and bit him on the hand. The children were bitten while at play. One was on the veranda of his home and the other was playing in the

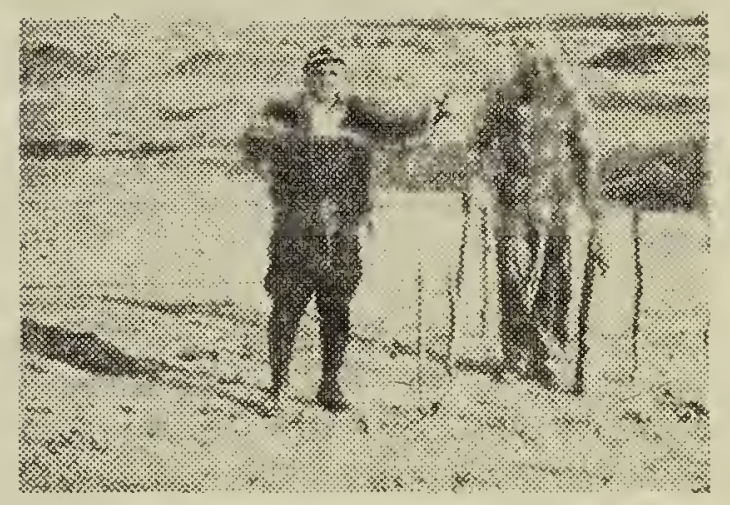

yard. Both were bitten at the ankle, as the snake will not strike upjust ahead. All recovered after being in the hospital for about three weeks.

Rattlesnakes are fond of robbing birds' nests of both eggs and young. One farmer related to me how, just in time, he discovered a rattler working itself up inside his granary. Among the rafters there was a sparrow's nest with young. The snake was making its way along the sill towards the nest. These snakes also have the peculiar habit of coiling up in the nests of hen houses after they have eaten the eggs. 